\title{
A Study on the effect of online education in the Untect Society: Focusing on personal motivation and social motivation
}

\author{
Hong-Kun Chin, Professor, School of Communication, Kookmin Univ.,77, Jeongneung-ro, Seongbuk-gu, Seoul, \\ 02707, Korea, chin1101@kookmin.ac.kr \\ *Min-Jung Kim, Professor, Division of Media \& Advertising, Dongeui Univ. 176, Eongwang-ro, Busanjin-gu, \\ Busan, 47340,Korea, minjungk@deu.ac.kr \\ *Corresponding Author
}

\begin{abstract}
The purpose of this research is to obtain information by conducting empirical testing on the influence of corporate governance independent variables, Information asymmetry, and firm size on independent earnings management variables in manufacturing companies listed on the Indonesia Stock Exchange (IDX) in the 2016-2018 period. In this study there were 59 manufacturing companies selected and used as samples by using purposive sampling as a sampling technique and testing multiple linear regression analysis. This study explains the results of testing on the variable corporate governance and information asymmetry with the results that show no significant effect on earnings management while the firm size variable shows a positive and significant relationship to earnings management.
\end{abstract}

Keywords: On-line Education, Personal Motivation, Social Motivation, Engagement, Attitude toward issue content, eWOM

Received: 13.12 .2020

Accepted: 10.01 .2021

Published: 02.02.2021

\section{INTRODUCTION}

The dramatic development of information and communication technology (ICT) has led to the activation of online education in the field of education, and cases in which online education is being used as a primary method or a secondary method of operating various educational programs are introduced in universities. As it becomes possible to overcome the limitations of time and space through online education, researches to understand the particular characteristics of online education and examine the effects are being actively conducted.

Previous researches can be divided into two types: a study to identify variables that influence the effect of online education and a study to test the effect of online education. First, the variables that affect online education can be divided into five categories: factors related to the learner's background and characteristics, factors related to instructional design, factors related to the environment of online education, factors related to the human resources, factors related to the education content and task. [1] identify factors affecting academic achievement in terms of three aspects: student, teacher, school. 'Student-level factors' is related to the academic interest, academic environment and academic attitude. 'Teacher-level Factors' is related to the teaching-learning ability and curriculum. 'School effectiveness factors' is related to the leadership, cooperation, learning opportunities, learning time. Among them, he/she was argued that the 'learner level factors' had the most influence. As a representative variable of learner level factors, learning motivation can be suggested [2]. [3] argued that it is necessary to use psychological predictive variables such as motivation as internal variables that explain actual behavior. The learning motivation is expected to have a high impact on engagement with future classes and issues learned in classes.

However, most of the studies to verify the effectiveness of online education mainly investigate the influence of the class level, such as the learners' class satisfaction, participation, and learning satisfaction. Since the effect of education is not only the class itself, but also the change of learners' view, it is necessary to expand the scope of the effectiveness. Especially, higher education, such as universities, requires learners to induce high-level deep learning in which learners actively acquire knowledge, process information, create and recreate meaning beyond the passive paradigm that teachers provide knowledge and information and learners accept it[4]. Therefore, not only the level of satisfaction and the achievement of the class, but also the aspect of active exploration and sharing of the issues learned in class should be expanded and examined. In other words, while the traditional teaching focuses on passive learning in which learners learn the given content, the new teaching needs a learners effect as the subject 
of education, such as how to make learners actively learn. The aim of this study is to examine educational effects in a broad sense, such as whether online education can induce learners to continue to be interested in specific issues.

\section{Theoretical background \& Hypothesis}

In the field of education, effectiveness refers to the general aspects that appear after planning and carrying out learning. The effectiveness of learning outcomes have been measured in various ways, such as evaluating various activities performed during the learning process or post-evaluation after learning for a certain period of time. In previous studies on the online education, learning outcomes were defined as academic achievement, participation, and learning satisfaction, and learning effects were evaluated as learning satisfaction and learning outcomes. However, the previous approaches to evaluate the educational effects remain in the discussion of education itself, and it is necessary to review more extensive effects in order to reflect the characteristics of the online space. It means that it is necessary to make sure that learners are interested in specific issues through actual learning, and explore and exchange new information.

Online education consists of learners-centered programs. Therefore, learners can learn by themselves in the desired time and space, the amount of learning can be flexibly adjusted by learners, and it can be an effective means of information exchange. In particular, it is possible to dynamically construct knowledge by expanding the area of information exchange through online education. It provides access to a variety of vivid information and opinions, and can organize, express and elaborate own opinions. In addition, it is possible to construct dynamic knowledge while changing the depth and breadth of existing information by accessing the latest information. Based on these ideas, this study aims to examine the effects of learning on a broader level, such as, through online education, learners are constantly interested in specific issues and actively express their opinions. Here, learning motivation is used as a variable that affects engagement, which is a state of flow and immersion in the issue. This is because the motivation to learn more about a specific issue or consume related content is likely due to the motivation that stimulates it.

Learning motivation plays an important role as a variable that has been actively discussed in previous researches on online education. According to a study by [2], learning motivation is an important variable predicting class satisfaction and cognitive learning. When learners perform tasks, learners with high motivation learn harder and participate more actively than learners with relatively low motivation[5], and learning outcomes and transfer outcomes increase[6]. [7] classified learning motivation into internal and external motivations. Internal motivation refers to the satisfaction or enjoyment that learners feel for themselves through participation, and external motivation refers to acting on the assumption that this activity will affect certain outcomes or achievements, rather than because they are interested. [8] also suggested motivations by dividing into two types: personal and social. Personal motivation refers to the satisfaction or enjoyment he/she feel from learning itself. On the other hand, social motivation refers to the intention of having a specific behavior or attitude in order to play a role as a member of society, rather than because of interest. In other words, there may be a tendency to learn more specific issues learned in class and access content in order to gain a sense of satisfaction or accomplishment by themselves. It means that they may want to approach related issues because they perceived it as an important agenda of society or a topic of conversation.

Online education has an environment that is differentiated from real spaces, and by itself, it influences the social and psychological characteristics of participants. Therefore, active participation of learners is an important issue, so more motivation is required than in the existing offline classroom environment. This study tries to examine how learning motivation affects not only online education itself, but also more learning voluntarily.

The concept of flow in learning was suggested by [9]. He said that immersed people are intrinsically motivated, interested in challenging tasks, and fully focused on task performance. While immersed, they experience a loss of sense of time because they are not very conscious of themselves, and their actions and consciousness are combined into one, having a clear goal, receiving feedback from actions about the goal, and having full control over the action. In the field of communication, this concept is further extended and referred to as engagement[10]. It can be defined as the degree to which audiences exposed to message information or advertisement content understand, immerse, and focus on the information. [11] said that it is to focus attention and increase exploration capabilities by empathizing with the brand message and creating expectations for consumers. The definition of engagement implies concepts such as interest, satisfaction, relevance, concentration, immersion, and involvement, and refers to the degree to which people exposed to programs or advertisements understand, immerse, and focus on information. Therefore, it is a qualitative concept that regards 'how 
deeply' the information is grasped, satisfied, understood, and focused, and the effects of online education can be examined in more depth and detail.

Online education is a public education program for social adaptation and knowledge cultivation, and at the same time, it has a personalized characteristic that can be used flexibly and selectively according to the needs of learners. Therefore, when learners study an issue online, there is a possibility that both personal and social motivations have an effect. Motivation to access and learn about issues can increase flow and immersion with online media and educational content, which ultimately leads to increased engagement.

\section{H1: In online education, learners' personal motivations will have a positive effect on engagement. \\ H2: In online education, learners' social motivations will have a positive effect on engagement.}

It has been empirically verified through several previous studies that flow and immersion in learning is a variable related to academic achievement[12]. Learner's immersion in online education induces positive learning outcomes such as high satisfaction and achievement [13]. [14] verified that the flow and immersion in learning of American college learners is related to academic achievement, and a study on online MBA course students also found that flow and immersion in learning has an effect on academic achievement[15]. As such, online education that requires learner-led learning, it can be assumed that engagement, such as flow and immersion in learning, induces participation in learning activities and cooperative activities, and has a positive effect on achievement of learning goals. [16, 17] also demonstrated that learner's immersion induces high learning outcomes. [18] analyzed the number of learning activities, learner-learner interactions, and learner-teacher interactions according to the level of flow and immersion in learning in a study targeting college students who involved in online learning. As a result, it was found that the group with high level of flow and immersion in learning interacted with more learning activities.

Therefore, the increase of learner's immersion will have an effect on learning and actively searching for content on the issue in addition to the achievements of the online class itself. At this moment, the level of flow and immersion in learning should go beyond simply taking an online education program, actively seeking more information, specifying one's opinion, and exchanging it with others to elaborate it. Therefore, it is necessary to measure its effectiveness with engagement that has evolved from the concept of flow and immersion in learning.

Previous researches on engagement clarified that high engagement has a positive effect on an increase in behavioral intention and advertisement attidudes[19], an increase in message involvement, message reliability, message and advertisement attitudes[20]. As such, it can be predicted that the increase in engagement may affect not only the flow and immersion in online classes itself, but also the attitude toward information and behaviors such as social media sharing. Based on previous studies, the relationship between motivation and engagement, attitude toward issue content, and word of mouth intention on SNS was set as a hypothesis.

H3: Engagement in the field through online education will have a positive effect on attitudes toward issue content in the field.

H4: Engagement in the field through online education will have a positive influence on the word of mouth intention for SNS in the field.

H5: Attitudes toward specific issues through online education will have a positive effect on word of mouth intentions on SNS.

Based on theoretical discussions and hypotheses, this study designed a research model as shown in $<$ Figure $1>$. The aims of this study is to examine the impact of personal and social motivations that online education has on engagement on specific issues, and to examine the positive $(+)$ influence on attitudes toward issue content and word of mouth intentions on SNS, considering engagement as a parameter. The hypotheses of this study are verified through a structural equation model that has the advantage of being able to control measurement errors, easy use of parameters, and statistical evaluation of the model. 


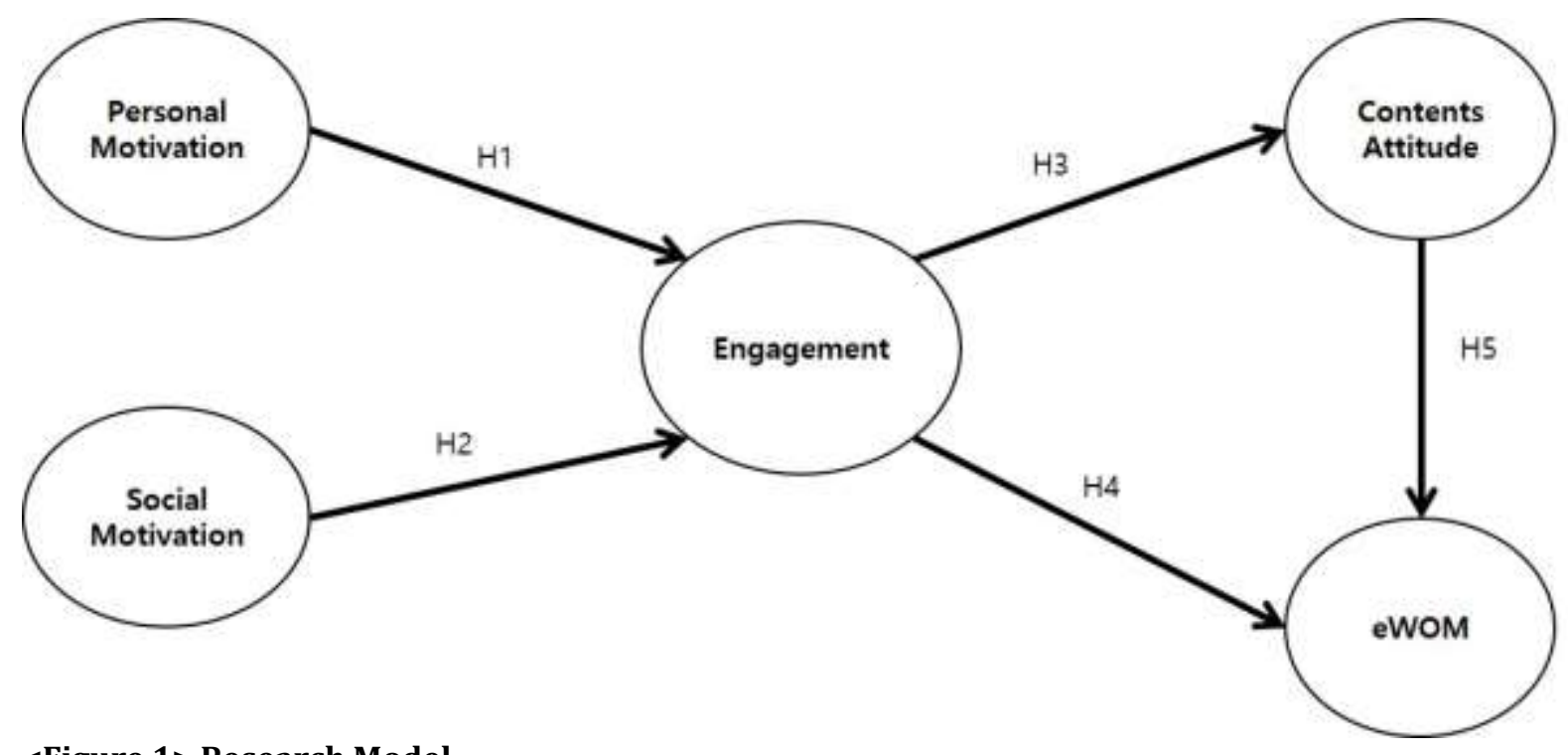

$<$ Figure 1> Research Model

\section{Methodology}

\subsection{Research subject and methodology}

For undergraduate students in the second semester 2, 2019 who took online lectures related to unification at universities located in the Gyeongnam, Korea, Republic Of., a survey was conducted to measure personal and social motivations, and their engagement with the topic of unification, attitudes toward contents, and word of mouth intentions on SNS. The data of the survey was reviewed in advance with the SPSS 18.0 program, and the hypothesis was verified through the structural model of the AMOS 19.0 program.

A total of 363 students answered to the survey, and data of 352 were finally analyzed, excluding 11 unfaithful respondents. The ratio of genders was $40.3 \%$ for males, 142 respondents and $59.7 \%$ for females, 210 respondents.

\subsection{Measurement of major variables}

For undergraduate students in the second semester 2, 2019 who took online lectures related to unification at universities located in the Gyeongnam, Korea, Republic Of., a survey was conducted to measure personal and social motivations, and their engagement with the topic of unification, attitudes toward contents, and word of mouth intentions on SNS. The data of the survey was reviewed in advance with the SPSS 18.0 program, and the hypothesis was verified through the structural model of the AMOS 19.0 program.

\subsection{Measurement of major variables}

In order to measure the endogenous variables, personal motivation and social motivation, motivation scale, suggested by [21] was applied. The personal and social motivational questions consisted of 4 questions respectively, and all were evaluated by using a 5-point Likert scale. The motivation scale for personal motivation includes questions as follows: 'unification-related content excites me', 'gives joy', 'enriches my heart', and 'improves my life'. The motivation scale for social motivation includes questions as follows: 'It will enrich my conversation topic', 'I will improve interpersonal relations', 'Because I can evaluate me well', and 'A social trend is expected and used.' As for the reliability of the measurement variables used in this study, Cronbach $\alpha=.91$ for personal motivation and Cronbach $\alpha=.88$ for social motivation were judged to be appropriate for use in analysis.

In this study, engagement variables are evaluated on a 5-point Likert scale on 7 questions that are modified the questions suggested by [20] which are related to interest, benefit, and flow/immersion. Measurement items includes follow questions: 'unification-related content caught my attention', 'I felt a strong desire to view unification-related content', 'I didn't know that time was passing while watching unification-related content', 'I have been immersed in the image of unification-related content. ', 'I have an urge to see unification-related content and visit related regions', 'unification-related content provides a variety of information', and 'unification-related content information is beneficial to me.' The reliability between the measurement variables by Cronbach $\alpha$ was adequate 0.90 . 
Lastly, the attitude toward specific issue (unification) content was measured on a 5-point Likert scale with [22]' three questions: "I like it," "I'm interested," and "I am generally satisfied". The reliability by Cronbach $\alpha$ was adequate 0.93 . SNS word of mouth intention is defined as the intention to introduce and inform other people through their own SNS[23], and the three questions suggested by [24] were measured on a 5-point Likert scale. The measurement questions includes follows: 'I will notify the unified content I have seen through my social media or mobile media', 'I will register and post the unified content on my social media or mobile media', and 'I will inform my social media about the unified content. I will talk through mobile media.' The reliability by Cronbach $\alpha$ was adequate 0.94 .

\section{Result discussions}

This study hypothesized that online education learners' engagement on specific issues would be positively (+) influenced by personal and social motivations. The engagements are expected to have a positive influence on attitudes toward issue-related content and word of mouth intentions on SNS. Before the analysis, correlation analysis on all variables to verify the causal structure was conducted and $<$ Table $1>$ summarized the result.

<Table 1> Analysis of correlation between variables

\begin{tabular}{|c|c|c|c|c|c|}
\hline & $\begin{array}{l}\text { Personal } \\
\text { Motivation }\end{array}$ & $\begin{array}{l}\text { Social } \\
\text { Motivation }\end{array}$ & Engagement & $\begin{array}{l}\text { Contents } \\
\text { Attitude }\end{array}$ & eWOM \\
\hline $\begin{array}{l}\text { Personal } \\
\text { Motivation }\end{array}$ & 1.00 & & & & \\
\hline $\begin{array}{l}\text { Social } \\
\text { Motivation }\end{array}$ & $.691^{* *}$ & 1.00 & & & \\
\hline Engagement & $.776^{* *}$ & $.660^{* *}$ & 1.00 & & \\
\hline $\begin{array}{l}\text { Contents } \\
\text { Attitude }\end{array}$ & $.693^{* *}$ & $.468^{* *}$ & $.769 * *$ & 1.00 & \\
\hline eWOM & $.529 * *$ & $.601^{* *}$ & $.532^{* *}$ & $.485^{* *}$ & 1.00 \\
\hline
\end{tabular}

Note: $\mathrm{p}<.05^{*} \mathrm{p}<.01^{* *} \mathrm{~N}=352$

Next, the hypotheses were tested by applying a structural equation model. There are two methods to evaluate the model, one is $X^{2}$ test and the other is the goodness-of-fit index. However, since it is known that the $X^{2}$ test is sensitive to the sample size, it is common not to evaluate the model entirely relying on the $X^{2}$ test. So this study evaluated the fitness of the model using RMSEA, TLI, and CFI those criteria of the fitness evaluation index were established referring previous studies. According to [25], if the RMSEA value is less than 0.05 , the good fit is from 0.05 to 0.08 , and if it is above 0.10 , it is inappropriate. In the case of TLI and CFI, they appear differently depending on the continuum from 1 to 0 , and if the value is more than 0.80 , it can be said that the suitability is good. As shown in $<$ Table 2>, it can be seen that the fitness of the model is satisfactory. Therefore, since the fitness of the model was verified, the hypotheses of this study was verified through the path coefficient estimated through the model.

$<$ Table 2> Fit of the research model $\mathrm{N}=352$

\begin{tabular}{lllllll}
\hline \multicolumn{1}{c}{$X^{2}$} & $\mathrm{df}$ & CFI & TLI & RMSEA \\
\hline Model & fit & 808.91 & 183 & .901 & .809 & .079 \\
\hline
\end{tabular}

From each parameter estimation results which presented in $<$ Table 3$\rangle$, it is clarified that personal motivation has a significant positive $(+)$ relationship to engagement. From the results, Hypothesis 1 was supported because the higher the personal motivation, the higher the engagement. Moreover, social motivation has a significant positive $(+)$ relationship with engagement, indicating that the higher the social motivation, the greater the engagement. The result supports Hypothesis 2.

<Table 3> Estimates of model parameters

\begin{tabular}{l|l}
\hline Regression Weights & Standardized Estimate \\
\hline Personal Motivation $\rightarrow$ Engagement & $.733^{* * *}$ \\
\hline Social Motivation $\rightarrow$ Engagement & $.180^{* * *}$ \\
\hline
\end{tabular}




\begin{tabular}{l|l}
\hline Engagement $\rightarrow$ Contents Attitude & $.841^{* * *}$ \\
\hline Engagement $\rightarrow \mathrm{eWOM}$ & $.609^{* * *}$ \\
\hline Contents Attitude $\rightarrow$ eWOM & -.004 \\
\hline Note: ${ }^{* * *} \mathrm{p}<.05$, &
\end{tabular}

Hypothesis 3, Hypothesis 4, and Hypothesis 5 identify the role of engagement affected by personal and social motivation. First, for the attitude toward engagement issues, it was found that there was a statistically significant positive (+) relationship, and the influence on SNS word of mouth intention also had a statistically significant positive (+) relationship. That is, it can be seen that as engagement increases, attitudes toward issues increase, and word of mouth on SNS also increases. However, it was not statistically significant whether the attitude toward the issue directly affected the word of mouth intention on SNS. Therefore, hypothesis 5 was rejected. The effect analysis according to the hypothesis relationship is presented in $<$ Figure $2>$.

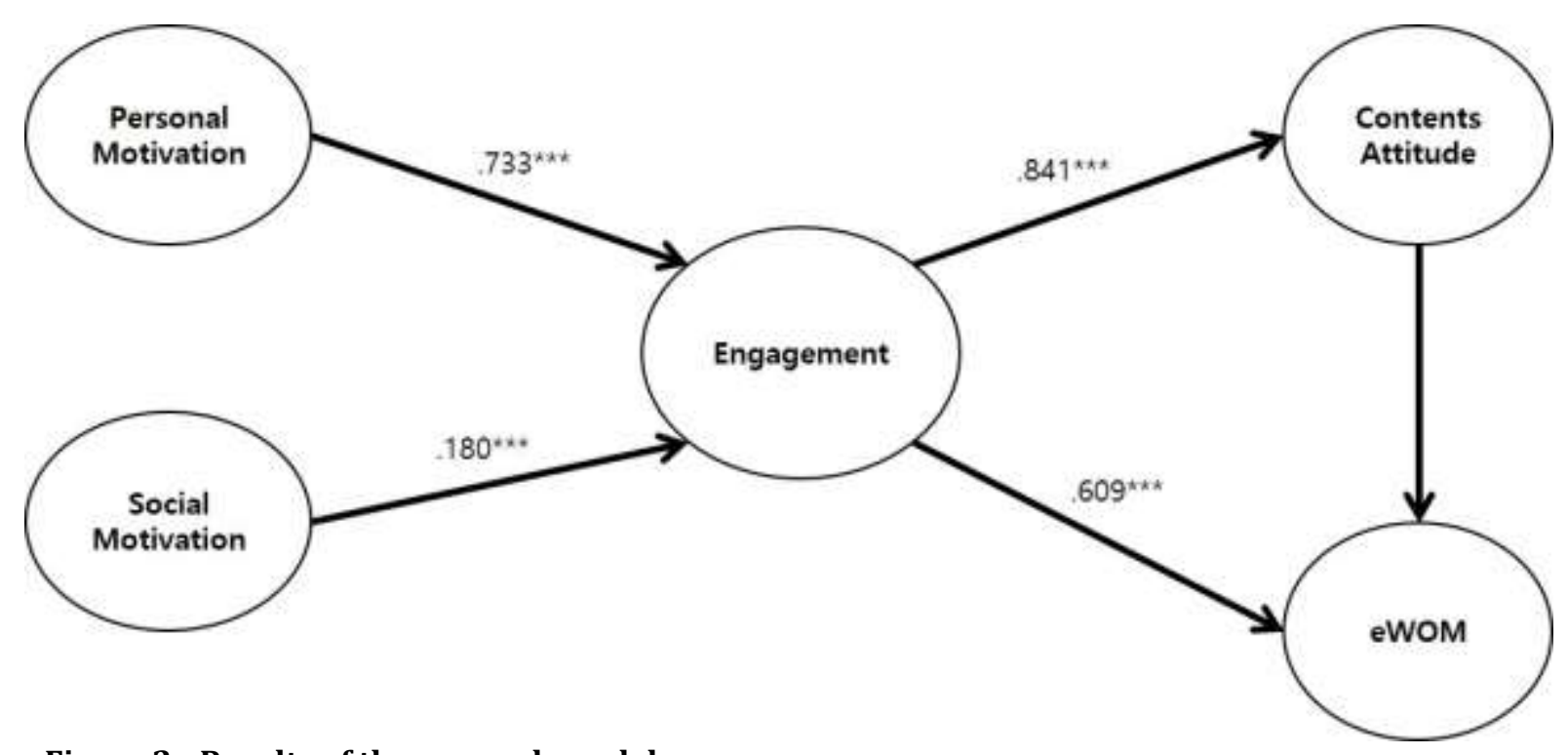

$<$ Figure 2> Results of the research model

\section{Conclusions}

The purpose of this study was to expand the effect of online education in terms of learners' satisfaction or sense of accomplishment for the class itself, and expand it with the intention of exchanging continuous interest and opinions on the issues of the class content. The result found that the engagement of learners who learned about specific issues through online classes was affected by both personal and social motivations. The results showed that engagement has a positive influence on the attitude of issue contents and word of mouth intention on SNS, but the attitude of issue contents did not affect the word of mouth intention on SNS.

These findings have several implications. First, for the relationship between motivation and engagement, it can be seen that personal motivation has more influence on increasing flow and immersion in class and engagement with the issue than social motivation. The results can be interpreted that a more active learning effect appears when interest in interpreting and structuring the issue is induced than when such lectures are considered more important for improving my social life or relationship. Online education has the advantage of overcoming the physical constraints of classroom space and providing enough educational materials to learners. In online environment, learners can learn on their own anytime, anywhere, and can check their abilities and aptitude through active selection. In this aspect, motivation through online classes to learners is an important factor that enables them to examine specific issues with interest, consume content related to issues, and express active opinions. It means that it is necessary not only to providing simple information, but also use a learning method that ensures various learning activities.

In addition, it will be necessary to consider how to utilize both personal and social motivations. Digitally-optimized humans like digital natives prefer to share common experiences, and think the more people talk about a particular issue, the more it will affect others. This is why it is important to look at the social motivation that is a tendency to establish itself as a member of society by sharing a specific experience. The recent online education is evolving from information transfer to a method that requires 
active participation of learners such as cooperative learning and discussion. For example, online cooperative learning promotes more divergent thinking, allows students to learn creativity and flexibility, and encourages free communication and sharing of ideas. In addition, online discussion activities gather members' opinions to help them solve problems creatively, and lead to flexible thinking in a horizontal human relationship. Therefore, it is necessary to think about how to increase their engagement by using these learning methods to increase their social motivation.

Finally, the result showed that increased engagement positively affects learners' attitudes toward issue content and their intention to word of mouth on SNS. In fact, the more flow and immersion in a class or issue increases, the higher the probability of making a positive judgment about the relevant content or the intention to learn related content. It means that it extends to the act of trying to share and share opinions with others. The results proved that the effect of online education can be associated not only to the satisfaction of classes and personal achievements, but to the active act of making a voice.

However, the attitude toward the found issue content did not affect to word of mouth intention, which seems to be because the person's rational judgment or thoughts about the content influence the word of mouth intention more than the feelings of like or dislike for the content. Therefore, comparative analysis on rational domains such as attitudes toward issue contents as well as beliefs on issues should be conducted as follow-up studies.

Consequently, the results of this study implies that it is necessary to establish a strategy that maximizes learning motivation in order to not only increase the level of participation of the learner during the class or satisfaction with the class itself and but also continue to be interested in educational issues or related content afterwards.

However, the results of this study have some limitations. First, the results of this study could not be generalized because it reflects on the special situation in Korea, Republic Of. The issue of unification is inevitably an issue with a very high level of involvement for undergraduate students, and therefore, it is highly likely that motivation and engagement were formed relatively high. The fact that the university in which related classes were held was selected as the leading university for unification and operated a number of educational programs focusing on unification education is likely to have an impact. Therefore, it is necessary to select and check other issues or regions. Second, research subjects were limited to undergraduate students who took online education at one university. Therefore, it is necessary to expand it to a variety of subjects for further study.

Finally, this study examined the effectiveness of education through motivation, engagement, attitude to issue content, and word of mouth on SNS. For the effective design of online education, it will be necessary to review factors within the program, such as the development process of learning content, interactivity, academic satisfaction and participation. Since the unexpected COVID-19 incident in 2019, education field are demanding high understanding and effective implementation of online education. In a situation where no one yet knows what the future holds for COVID-19, it is time to think about highquality online education. Hope this study provide a clue to these concerns.

\section{References}

[1] Marzano, R. J. (2001). A new era of school reform going where the research takes us. Aurora, CO: Midcontinent Research for Education and Learning.

[2] Lim D. H., Morris, M. L. \& Yoon W. (2006). Instructional and learner factors influencing learning outcomes with online learning environment. Online Submission https://files.eric.ed.gov/fulltext/ED492786.pdf.

[3] Mehmetogh, M. (2012). Personality effects on experimental consumption. Personality and Individual Differences. 52, 94-99.

[4] Garrison, D. R., \& Anderson, T. (2003). E-learning in the 21th century: A framework for research and practice. RoutledgeFalmer, London.

[5] Jonassen, D., Davison, M., Collins, M., Campbell, J., \& Haab, B. B. (1995). Constructivism and computermediated communication in distance education. The American Journal of Distance Education, 9(2), 725.

[6] Nam, K. C., Lim, H. C., \& Hwang, K. J. (2002). A study of On-line on training effectiveness. Journal of the Korean Operation Research and Management Science Society. 27(1), 75-94. http://www.dbpia.co.kr/journal/articleDetail?nodeId=NODE00310503

[7] Pintrich, P. R., DeGroot, E. V. (1990). Motivational and self-regulated learning components of classroom academic performance. Journal of Education Psychology. 82(1), 33-40.

[8] Sorrentino, R. M., \& Higgins, E. T. E. (1986). Handbook of motivation and cognition: Foundations of social behavior. Guilford Press, New York.

[9] Csikszentmihalyi, M. (1990). Flow: The psychology of optimal experience. Harper \& Row, New York. 
[10] Higgins, E. T. (2006). Value from hedonic experience and engagement. Psychological review, 113(3), 439.

[11] Friedlein, A.(2006). Web 2.0-what are the metrics for successful 'engagement'? http://www.econsultancy.com

[12] Chen, P. D., Gonyea, R., \& Kuh, G. (2008). Learning at a distance : Engaged or Not?. Innovate, 4-3, 1-7.

[13] Pearce, J. (2005). Engaging the learner: how can the flow experience support e-learning?. In E-Learn: World Conference on E-Learning in Corporate, Government, Healthcare, and Higher Education, Association for the Advancement of Computing in Education (AACE), 2288-2295.

[14] Carini, R. M., Kuh, G. D., \& Klein, S. P. (2006). Student engagement and student learning: Testing the linkage. Research in Higher Education, 47(1), 1-32.

[15] Rossin, D., Ro, Y. K., Klein, B. D., \& Guo, Y. M. (2009). The effects of flow on learning outcomes in an online information management course, Journal of Information Systems Education, 20(1), 87-98.

[16] Webster, J. \& Hackley, P. (1997). Teaching effectiveness in technology-mediated distance learning. Academy of Management Journal, 40(6), 1282-1309.

[17] Liu, X., Bonk, C. J., McIntyre, S., \& Magjuka, R. (2008). An investigation of the relationship between flow in computer-mediated interaction and virtual learning team effectiveness. In E-Learn: World Conference on E-Learning in Corporate, Government, Healthcare, and Higher Education, Association for the Advancement of Computing in Education (AACE), 1(1), 2919-2928.

[18] Dixon, M. D. (2010). Creating effective student engagement in online courses: What do students find engaging?. Journal of the Scholarship of Teaching and Learning, 10(2), 1-13.

[19] Calder, B. J., Malthouse, E. C., \& Schaedel, U.(2009). An experimental study of the relationship between online engagement and advertising effectiveness. Journal of Interactive Marketing, 23, 321 331.

[20] Wang, A. (2006). Advertising Engagement: A driver of message involvement on message effects. Journal of Advertising Research, 46(4), 355-368. https://doi.org/10.2501/S0021849906060429

[21] Tao (2013). Personality, Motivation, and Behavioral intentions in the experiential consumption of $\begin{array}{lll}\text { artworks. Social behavior and Personality, 41(9), 1533-1546. } & \text {. }\end{array}$ http://dx.doi.org/10.2224/sbp.2013.41.9.1533

[22] Gardner, M. P. (1985). Mood sates and consumer behavior: A critical review. Journal of Consumer Research, 12, 281-300.

[23] Constant, D., L. Sproull, \& S. Kiesler (1997). The kindness of strangers: On the usefulness of electronic weak ties for technical advice. In S. Kiesler (Ed.), Culture of the Internet (303-322). Mahweh, Lawrence Erlbaum, NJ.

[24] Chin, Oh \& lee (2014). Determinants of electronic Word-of-Mouth (eWOM) and purchase intention in digital signage advertising (DSA). International Journal of Applied Engineering Research, 9(21), 91499156.

[25] Browne, M., \& Cudeck, R. (1993). Altenative ways of Assessing model fit. In K. A. Bollen \& J. S. Long(Eds.), Testing structural equation models, 136-162, Newbury Park, CA:Sage. 